Check for updates

Cite this: RSC Adv., 2020, 10, 29175

\title{
First principles study of electrocatalytic behavior of olivine phosphates with mixed alkali and mixed transition metal atoms $\uparrow$
}

\begin{abstract}
Arup Chakraborty, (D) Sooraj Kunnikuruvan, David Zitoun (DD and Dan T. Major (DD *
Lithium transition metal olivine phosphates are well known Li-ion battery cathode materials, but these materials can also be used as electrocatalyst. Recent experimental studies showed that olivine phosphates with mixed alkali metals ( $\mathrm{Li}$ and $\mathrm{Na}$ ) and mixed transition metals ( $\mathrm{Ni}$ and Fe) provide better electrocatalytic activity compared to single alkali and transition metal alternatives. In the current work, we analyzed the role of alkali metals, transition metals and vacancies on the reactivity of a series of olivine phosphates with different stoichiometries using first principles calculations. To this end, we investigated the adsorption of water at the surface of these materials. We found that water binds preferably at Ni surface sites for materials devoid of alkali ion vacancies. We further found correlation between the calculated adsorption energy with experimentally measured overpotentials for a series of olivine phosphates. Additionally, we found correlation between the adsorption energy of the systems with the total charge polarization of surface and adsorbate. To explain the computed trends, we analyzed the occupancies of the partial density of states of the $\mathrm{Ni}$ and Fe $3 \mathrm{~d}$ states and Bader atomic

charges.
\end{abstract}

Received 20th March 2020
Accepted 27th July 2020

DOI: 10.1039/d0ra02577a

rsc.li/rsc-advances

\section{Introduction}

Lithium transition-metal olivine phosphates with the general formula $\mathrm{LiMPO}_{4}(\mathrm{M}=\mathrm{Fe}, \mathrm{Co}, \mathrm{Ni}, \mathrm{Mn})$ are promising and environmentally benign energy storage materials applied as positive electrodes in Li-ion batteries. These materials are cost effective and provide good thermal stability during lithiation and delithiation. ${ }^{1-5}$ However, olivine phosphates with single transition-metal (TM) composition, such as $\mathrm{LiFePO}_{4}$, suffer from low electronic conductivity and poor redox kinetics. ${ }^{6}$ There are many recent studies on mixed transition metal olivine systems $\left(\mathrm{LiM}_{1-x} \mathrm{M}_{x}^{\prime} \mathrm{PO}_{4} ; \mathrm{M}\right.$ and $\left.\mathrm{M}^{\prime}=\mathrm{Fe}, \mathrm{Ni}, \mathrm{Co}, \mathrm{Mn}\right)$ by various group which have shown ability to overcome these issues. ${ }^{7-13}$ Beyond this, the olivine phosphates are also known as good electrocatalyst for oxygen evolution reactions (OER). ${ }^{14-17}$ Excellent OER electrocatalysts, such as ruthenium, iridium and their oxides exist, but these are costly, ${ }^{18-23}$ and there is an ongoing search for non-noble metal catalysts for OER. ${ }^{24-29}$ Olivine phosphate materials can provide cost-effective alternatives to noble metal catalysts like Pt and Ir, and Fe doped Ni- and Cobased olivine phosphate were found to be promising OER active materials. ${ }^{30,31}$ Recently Gershinsky et al. synthesized

Department of Chemistry, Institute for Nanotechnology \& Advanced Materials, Bar-Ilan University, Ramat-Gan 52900, Israel. E-mail: majort@biu.ac.il; Fax: +972 3 73840 53; Tel: +97235317392

† Electronic supplementary information (ESI) available. See DOI: 10.1039/d0ra02577a mixed alkali (Li/Na) and mixed transition metal olivine phosphates and tested their OER activity. ${ }^{32,33}$ They showed that a particular combination of alkali metals ( $\mathrm{Li}$ and $\mathrm{Na}$ ) and transition metals with specific ( $1 \mathrm{M}$ to $6 \mathrm{M}$ ) $\mathrm{KOH}$ concentration can be an excellent OER catalyst. Moreover, this study also indicated that defects in the olivine phosphate improved the OER catalytic activity.

Olivine phosphates belong to the olivine family which has an orthorhombic structure within the Pnma space group. In olivine structures, $\mathrm{Li}$ ions are arranged in edge sharing octahedra and transition metals (TMs) are in a corner sharing octahedral environment with oxygen atoms, whereas phosphorus ions are in a tetrahedral environment. The strong $\mathrm{P}-\mathrm{O}$ covalent bonds provide the material with good thermodynamic stability, by reducing the release of oxygen. ${ }^{6}$ Morgan et al. showed that $\mathrm{Li}$ ions diffuse in one dimensional channels along the $b$-direction (i.e. the [010] direction in Pnma structures). ${ }^{34}$ Later Islam et al. employed computational modelling to show that the [010] direction is the favorable one for Li diffusion, while Nishimura et al. reached the same conclusion using an experimental approach. ${ }^{35-37}$ Further Wang et al. found that the (010) surface plane has lower surface energy compare to other planes, like (100) and (101)..38

In the present work, we perform first principles-based computations to understand the effect of mixed alkali and transition metals and defects on the reactivity of olivine phosphates by looking at the adsorption of water on the surface of these materials. OER involves different intermediate steps 
where binding of $\mathrm{H}_{2} \mathrm{O}, \mathrm{OH}, \mathrm{O}, \mathrm{OOH}$ occurs at the metal site of the surface of the electro-catalyst. ${ }^{\mathbf{1 6 , 3 9}}$ It has been shown in earlier studies that these different steps are linearly correlated. ${ }^{15,16,40-45}$ Thus, the metal-oxygen interaction along the OER cascade is likely to play an important role in the rate limiting step. ${ }^{\mathbf{4 0 , 4 5 , 4 6}}$ Although water binding is presumably not the rate limiting step for OER, ${ }^{\mathbf{1 6}, 46}$ water binding is expected to reflect on the ability of the olivines to bind oxygen. Here, we systematically explore the binding of a water molecule at the surfaces of mixed alkali and mixed transition metal olivine phosphate using density functional theory (DFT) calculations. Our studies mainly focus on $\mathrm{Li}_{0.8} \mathrm{Na}_{0.2} \mathrm{Ni}_{0.7} \mathrm{Fe}_{0.3} \mathrm{PO}_{4}$ without and with Livacancies. We further chose four different compounds $\mathrm{LiNiPO}_{4}, \mathrm{LiNi}_{0.7} \mathrm{Fe}_{0.3} \mathrm{PO}_{4}, \mathrm{LiNi}_{0.8} \mathrm{Co}_{0.2} \mathrm{PO}_{4}$, and $\mathrm{LiNi}_{0.9} \mathrm{Fe}_{0.1} \mathrm{PO}_{4}$, respectively for a comparative study following the work of Gershinsky et $a l .{ }^{33}$ Based on these studies we qualitatively correlate between the observed electrochemical activity for OER and the probability of binding water on the surface of these materials with and without Li-vacancies. To the best of our knowledge, this is the first computational study focusing on the surface reactivity of olivine phosphate-based materials with application to OER.

\section{Methods and models}

\subsection{Computational details}

All the calculations were performed using plane wave-based DFT, as implemented in the Vienna $A b$ initio Simulation Package (VASP). ${ }^{\mathbf{4 7} 48}$ We employ projector augmented wave (PAW) potentials, ${ }^{49}$ in conjunction with the Perdew-BurkeErnzerhof (PBE) functional ${ }^{50}$ with Hubbard- $U$ correction ${ }^{51}$ (Dudarev's method ${ }^{52}$ ). The applied effective value of $U$ for Ni, Co, and $\mathrm{Fe}$ are $5.96,5.7$, and $4.3 \mathrm{eV}$, respectively. ${ }^{7}$ The cut-off energy value for the plane wave basis was set to $520 \mathrm{eV}$. The convergence limit for the energy in a self-consistent run was set to $10^{-5} \mathrm{eV}$, whereas $0.01 \mathrm{eV} \AA^{-1}$ was used for the force convergence per atoms during geometry optimization. We chose a $\Gamma$ centered $k$-mesh of $8 \times 4 \times 1$ to sample the irreducible part of the Brillouin zone.

\subsection{Structural model}

We considered four formula units to model a bulk orthorhombic structure of $\mathrm{LiNiPO}_{4}$ within the Pnma space group. To find the adsorption energy of water at the surface of the olivine phosphates, we generated a (010) plane surface slab, as this plane is the most stable. ${ }^{35-37}$ The slab model was created from an optimized bulk unit cell, and the slab model was reoptimized after generation. The lattice parameters for the surface slab model are ca. $4.8 \AA$ and $10.2 \AA$. The thickness of the slab is approximately $13.7 \AA$, as this thickness produces converged values for calculated surface energies, as reported by Wang et $a l .{ }^{38} \mathrm{~A}$ vacuum of $20 \AA$ in the [010]-direction is employed to nullify the periodic image effect normal to the (010) plane. Our surface slab constitutes 10 formula units of $\mathrm{LiMPO}_{4}$. In this stoichiometric surface slab, one end is terminated with Li ions and other end is terminated with TMs. One water molecule is

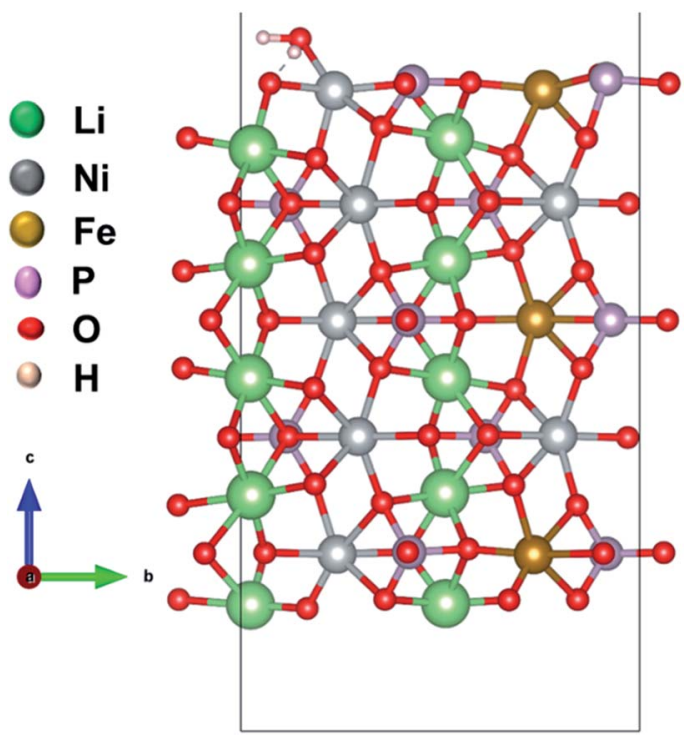

Fig. 1 Model of a (010) surface slab with a water molecule adsorbed to $\mathrm{Li}_{10} \mathrm{Ni}_{7} \mathrm{Fe}_{3} \mathrm{P}_{10} \mathrm{O}_{40}$. $\mathrm{Li}, \mathrm{Ni}, \mathrm{Fe}, \mathrm{P}$, and $\mathrm{O}$ are in green, grey, brown, magenta and red color, respectively.

attached to a TM site as shown schematically in Fig. 1 and S1 in ESI. $\dagger$

\section{Results and discussion}

In the following paragraphs we will first discuss bulk material properties, followed by a discussion of the electronic structure of the (010) surface and the adsorption of a single water molecule on this surface for different combinations of alkali and transition metals with and without defects.

Initially, we consider bulk orthorhombic $\mathrm{LiNiPO}_{4}$ within the Pnma space group. In this system, we find that the antiferromagnetic configuration is more stable than the ferromagnetic configuration by $28 \mathrm{meV}$ (see Table S1 in ESI†). From electronic structure calculations, we observed that $\mathrm{Ni}$ is in a $2+$ oxidation state and in a high spin state (calculated moments of $\mathrm{Ni}$ ions are $c a$. $1.8 \mu_{\mathrm{B}}$ ). In these pure systems we introduce one $\mathrm{Na}$ atom within the bulk unit cell consisting of four formula units. The formation energy $\left(\Delta E_{\mathrm{f}}\right)$ is calculated using the following formula for $\mathrm{Na}$ doping at a Li site:

$$
\Delta E_{\mathrm{f}}=E\left(\mathrm{Li}_{0.75} \mathrm{Na}_{0.25} \mathrm{MPO}_{4}\right)-E\left(\mathrm{LiMPO}_{4}\right)-\mu(\mathrm{Na})+\mu(\mathrm{Li})
$$

where $E\left(\mathrm{Li}_{0.75} \mathrm{Na}_{0.25} \mathrm{MPO}_{4}\right)$ and $E\left(\mathrm{LiMPO}_{4}\right)$ are the ground state energies of $\mathrm{Li}_{0.75} \mathrm{Na}_{0.25} \mathrm{MPO}_{4}$ and $\mathrm{LiMPO}_{4}$ respectively. $\mathrm{M}$ is a TM, like Ni. Based on these calculations, we find that $\mathrm{Na}$ preferably replaces $\mathrm{Li}$ in $\mathrm{LiNiPO}_{4}$ system (see Table S2 in $\mathrm{ESI} \dagger$ ). Further we model a bulk unit cell in the presence of Li-vacancies (25\%) and find that $\mathrm{Na}$ replaces $\mathrm{Li}$ in $\mathrm{Ni}-\mathrm{Fe}$ mixed $\mathrm{TM}$ material. Replacement of $\mathrm{Li}$ by $\mathrm{Na}$ is expected since both $\mathrm{Li}$ and $\mathrm{Na}$ ions are in a +1 oxidation state.

We now compare the density of states (DOS) of the bare surfaces of $\mathrm{LiNi}_{0.7} \mathrm{Fe}_{0.3} \mathrm{PO}_{4}$ (Fig. 2a) and $\mathrm{Li}_{0.8} \mathrm{Na}_{0.2} \mathrm{Ni}_{0.7} \mathrm{Fe}_{0.3} \mathrm{PO}_{4}$ (Fig. 2b). We observe that TM-3d states appearing near the 

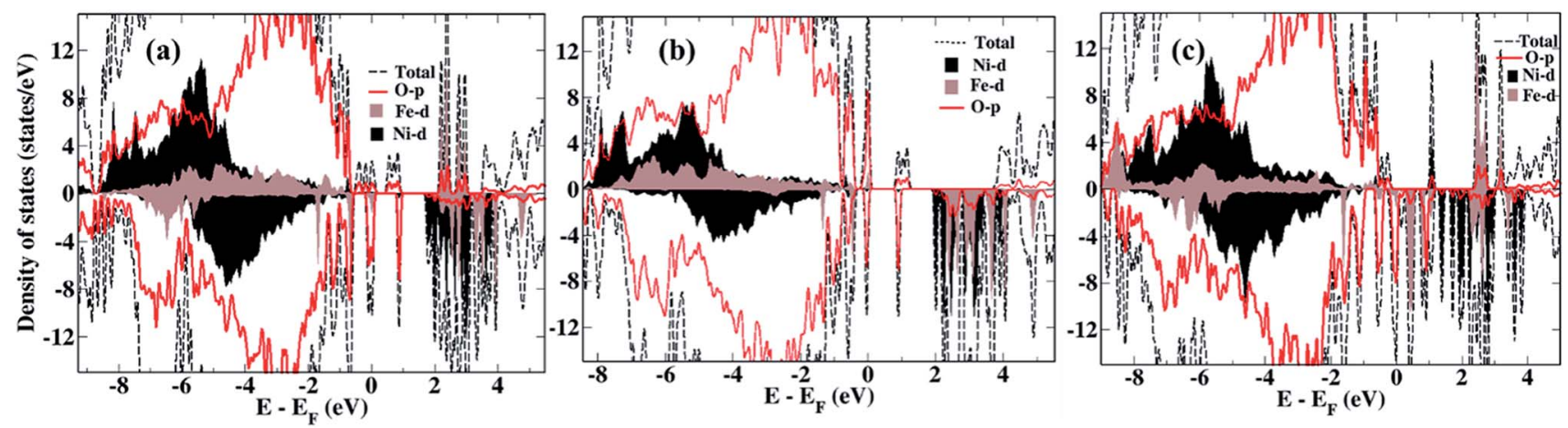

Fig. 2 Density of states of the bare surfaces of (a) $\mathrm{LiNi}_{0.7} \mathrm{Fe}_{0.3} \mathrm{PO}_{4}$, (b) $\mathrm{Li}_{0.8} \mathrm{Na}_{0.2} \mathrm{Ni}_{0.7} \mathrm{Fe}_{0.3} \mathrm{PO}_{4}$, (c) $\mathrm{Li}_{0.6} \mathrm{Na}_{0.2} \mathrm{Ni}_{0.7} \mathrm{Fe}_{0.3} \mathrm{PO}_{4}$.

Fermi energy mainly consist of Fe-3d orbitals, while the conduction band consists of Ni-3d states for both $\mathrm{LiNi}_{0.7} \mathrm{Fe}_{0.3^{-}}$ $\mathrm{PO}_{4}$ and $\mathrm{Li}_{0.8} \mathrm{Na}_{0.2} \mathrm{Ni}_{0.7} \mathrm{Fe}_{0.3} \mathrm{PO}_{4}$ when there are no Li-vacancies. Hence, we expect that $\mathrm{Ni}$ ions will be reduced first during water adsorption rather than $\mathrm{Fe}$, due to the presence of antibonding $\mathrm{Ni}-3 \mathrm{~d}$ states. In presence of Li-vacancies (e.g. $\mathrm{Li}_{0.6} \mathrm{Na}_{0.2} \mathrm{Ni}_{0.7^{-}}$ $\mathrm{Fe}_{0.3} \mathrm{PO}_{4}$ ), the scenario is different as both the occupied and unoccupied levels near the Fermi level are composed of Fe-3d states (Fig. 2c). Hence, water is expected to adsorb at Fe-sites in the case of Li-vacancies.

Further, we calculated the adsorption energy of water to understand the difference in reactivity of these surfaces. The formula for the adsorption energy $\left(\Delta E_{\mathrm{ads}}\right)$ is

$$
\begin{gathered}
\Delta E_{\text {ads }}=E\left(\mathrm{Li}_{x} \mathrm{Na}_{y} \mathrm{Ni}_{0.7} \mathrm{Fe}_{0.3} \mathrm{PO}_{4} \cdot \mathrm{H}_{2} \mathrm{O}\right)-E\left(\mathrm{Li}_{x} \mathrm{Na}_{y} \mathrm{Ni}_{0.7} \mathrm{Fe}_{0.3} \mathrm{PO}_{4}\right) \\
-E\left(\mathrm{H}_{2} \mathrm{O}\right)
\end{gathered}
$$

where $\quad E\left(\mathrm{Li}_{x} \mathrm{Na}_{y} \mathrm{Ni}_{0.7} \mathrm{Fe}_{0.3} \mathrm{PO}_{4} \cdot \mathrm{H}_{2} \mathrm{O}\right), \quad E\left(\mathrm{Li}_{x} \mathrm{Na}_{y} \mathrm{Ni}_{0.7} \mathrm{Fe}_{0.3} \mathrm{PO}_{4}\right)$, $E\left(\mathrm{H}_{2} \mathrm{O}\right)$ are the energies of $\mathrm{Li}_{x} \mathrm{Na}_{y} \mathrm{Ni}_{0.7} \mathrm{Fe}_{0.3} \mathrm{PO}_{4}$ with a water molecule, bare surface of $\mathrm{Li}_{x} \mathrm{Na}_{y} \mathrm{Ni}_{0.7} \mathrm{Fe}_{0.3} \mathrm{PO}_{4}$ and a single water molecule, respectively. The (010) surface of $\mathrm{LiNi}_{0.7} \mathrm{Fe}_{0.3} \mathrm{PO}_{4}$ and $\mathrm{Li}_{0.8} \mathrm{Na}_{0.2} \mathrm{Ni}_{0.7} \mathrm{Fe}_{0.3} \mathrm{PO}_{4}$ with mixed transition metals, like $\mathrm{Ni}$ and $\mathrm{Fe}$, contain two different metal atoms, Ni and $\mathrm{Fe}$ at the surface. Hence, the adsorption of a single water molecule can occur at any of Ni or Fe sites. The calculated adsorption energies at both TM sites are presented in Table 1.

From the calculation of adsorption energy of a water molecule at different TM sites, we observe that the Ni site is preferable in the absence of $\mathrm{Li}$ vacancies (Table 1 ), in agreement with the expectation based on the computed DOS (vide supra).
Moreover, both $\mathrm{Ni}$ and $\mathrm{Fe}$ are in a $2+$ oxidation state, and the reduction potential of $\mathrm{Ni}^{2+}$ is higher than $\mathrm{Fe}^{2+}$, hence also supporting water adsorption at $\mathrm{Ni}$ sites. Unlike the above systems which are devoid of vacancies, the introduction of vacancies was found to change the favorable adsorption site from $\mathrm{Ni}$ to $\mathrm{Fe}$ as indicated by the adsorption energy calculations for $\mathrm{Li}_{0.8} \mathrm{Ni}_{0.7} \mathrm{Fe}_{0.3} \mathrm{PO}_{4}$ (Table 1). The preference for Fe sites can be ascribed to the presence of unoccupied states which consist of Fe 3d states closer to the Fermi level than the Ni 3d states, as discussed above.

In the absence of alkali ion vacancy, doping $\mathrm{LiNi}_{0.7} \mathrm{Fe}_{0.3} \mathrm{PO}_{4}$ with $\mathrm{Na}$ does not affect water adsorption to this surface significantly, as indicated by the comparable adsorption energy to that of $\mathrm{Li}_{0.8} \mathrm{Na}_{0.2} \mathrm{Ni}_{0.7} \mathrm{Fe}_{0.3} \mathrm{PO}_{4}$ (Table 1). However, the presence of alkali ion vacancy was found to increase the reactivity of the system significantly, as indicated by the reduction in adsorption energy of $\mathrm{Li}_{0.8} \mathrm{Ni}_{0.7} \mathrm{Fe}_{0.3} \mathrm{PO}_{4}$ by about $0.46 \mathrm{eV}$ and the reduction in adsorption energy of $\mathrm{Li}_{0.6} \mathrm{Na}_{0.2} \mathrm{Ni}_{0.7} \mathrm{Fe}_{0.3} \mathrm{PO}_{4}$ by about $0.55 \mathrm{eV}$ compared to $\mathrm{LiNi}_{0.7} \mathrm{Fe}_{0.3} \mathrm{PO}_{4}$ and $\mathrm{Li}_{0.8} \mathrm{Na}_{0.2} \mathrm{Ni}_{0.7} \mathrm{Fe}_{0.3} \mathrm{PO}_{4}$, respectively. Further a comparison of adsorption energies of $\mathrm{Li}_{0.8} \mathrm{Ni}_{0.7} \mathrm{Fe}_{0.3} \mathrm{PO}_{4}$ and Na-doped $\left(\mathrm{Li}_{0.6} \mathrm{Na}_{0.2} \mathrm{Ni}_{0.7} \mathrm{Fe}_{0.3} \mathrm{PO}_{4}\right)$ indicates that Na doping have minor effect on water binding also in the presence of Li-vacancies. These results suggest that the increase in reactivity is largely due to the presence of vacancies and to a smaller extent Na-doping. We note that $\mathrm{Li}_{0.8} \mathrm{Ni}_{0.7^{-}}$ $\mathrm{Fe}_{0.3} \mathrm{PO}_{4}$ was difficult to synthesize as indicated by Gershinsky et al., ${ }^{33}$ whereas $\mathrm{Li}_{0.6} \mathrm{Na}_{0.2} \mathrm{Ni}_{0.7} \mathrm{Fe}_{0.3} \mathrm{PO}_{4}$ is reported in experiments.

We further calculated the difference in charge density after calculating charge density along the grid points for the bare

Table 1 Adsorption energy (eV) for a single water molecule in $\mathrm{Li}_{x} \mathrm{Na}_{y} \mathrm{Ni}_{0.7} \mathrm{Fe}_{0.3} \mathrm{PO}_{4}$ at different $\mathrm{TM}$ sites

$\Delta E_{\text {ads }}(\mathrm{eV})$

Systems

Water molecule attached at Ni site

Water molecule attached at Fe site

$\mathrm{LiNi}_{0.7} \mathrm{Fe}_{0.3} \mathrm{PO}_{4}$

$\mathrm{Li}_{0.8} \mathrm{Na}_{0.2} \mathrm{Ni}_{0.7} \mathrm{Fe}_{0.3} \mathrm{PO}_{4}$

$\mathrm{Li}_{0.8} \mathrm{Ni}_{0.7} \mathrm{Fe}_{0.3} \mathrm{PO}_{4}$

$\mathrm{Li}_{0.6} \mathrm{Na}_{0.2} \mathrm{Ni}_{0.7} \mathrm{Fe}_{0.3} \mathrm{PO}_{4}$
$-0.372$

$-0.299$

$-1.280$

$-1.309$ 
Table 2 Total charge polarization for different systems

\begin{tabular}{lll}
\hline System & $\begin{array}{l}\text { Total charge polarization } \\
\text { (electron charge/cell volume })\end{array}$ & $\begin{array}{l}\text { Adsorption energy } \\
\left(\Delta E_{\text {ads }}\right)(\mathrm{eV})\end{array}$ \\
\hline $\mathrm{Li}_{0.8} \mathrm{Na}_{0.2} \mathrm{Ni}_{0.7} \mathrm{Fe}_{0.3} \mathrm{PO}_{4}$ & $1.85 \times 10^{-4}$ & -0.763 \\
$\mathrm{LiNi}_{0.7} \mathrm{Fe}_{0.3} \mathrm{PO}_{4}$ & $1.95 \times 10^{-4}$ & -0.817 \\
$\mathrm{Li}_{0.8} \mathrm{Ni}_{0.7} \mathrm{Fe}_{0.3} \mathrm{PO}_{4}$ & $6.93 \times 10^{-4}$ & -1.280 \\
$\mathrm{Li}_{0.6} \mathrm{Na}_{0.2} \mathrm{Ni}_{0.7} \mathrm{Fe}_{0.3} \mathrm{PO}_{4}$ & $7.00 \times 10^{-4}$ & -1.309
\end{tabular}

surface, surfaces with water, and for the water molecule at the same position (in absence of slab) using the following formula: ${ }^{53}$

$$
\Delta \rho=\rho(\text { surface with water })-\rho(\text { bare surface })-\rho(\text { water })
$$

Here $\rho$ (surface with water), $\rho$ (bare surface), and $\rho$ (water) are the charge densities for the respective systems. Then we estimated the charge polarization between systems by multiplying $\Delta \rho$ with the volume of the unit cell and with electronic charge, as shown in Table 2.

We observed that the adsorption energy increases (absolute values) with increasing charge polarization upon water binding to the surface slab. The charge polarization is more prominent in the presence of Li-vacancies than the doping of Na. Hence, these results also reveal that the reactivity is increased due to the presence of vacancies rather than Na-doping and this is accompanied by greater charge polarization.

We further calculated Bader charges at the atom sites (see Tables S3 and S4 in ESI $\dagger$ ) following the method proposed by the Henkelman group..$^{54,55}$ Based on this electronic structure analysis we provide a rationale for the lower adsorption energy of $\mathrm{Li}_{0.6} \mathrm{Na}_{0.2} \mathrm{Ni}_{0.7} \mathrm{Fe}_{0.3} \mathrm{PO}_{4}$. The $\mathrm{Ni}$ and Fe atoms at the top of the surface slab have lower Bader charges compared to atoms within the bulk of the slab due to the presence of dangling bonds at the surface. The same is true for $\mathrm{P}$ atoms and $\mathrm{O}$ atoms at the surface which have two neighboring metal atoms. There are substantial changes in the Bader charge of Fe atoms at the top of the surface and at the subsurface near the bottom layer in

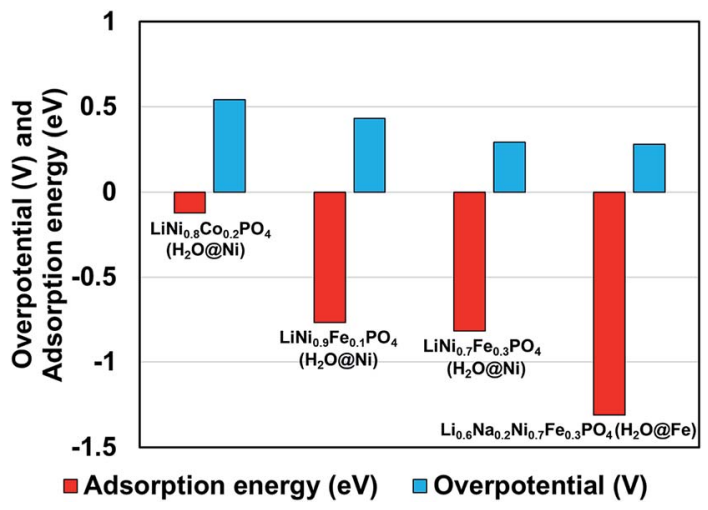

Fig. 3 Comparison of calculated adsorption energy and experimentally ${ }^{14,33}$ measured overpotential for the olivine phosphates with mixed alkali and TM atoms. our model. Introduction of $\mathrm{Na}$ and presence of Li-vacancies affect the Bader charge as well and this is also observed from the change in the moment of Fe from $c a .3 .8 \mu_{\mathrm{B}}$ to $4.2 \mu_{\mathrm{B}}$. This can be attributed to the change in bond length of the atoms to adopt the bigger sized $\mathrm{Na}$ atoms. Next, we observed that $\mathrm{Ni}$ and $\mathrm{Fe}$ atoms in the top layer have higher Bader charge values for $\mathrm{Li}_{0.6} \mathrm{Na}_{0.2} \mathrm{Ni}_{0.7} \mathrm{Fe}_{0.3} \mathrm{PO}_{4}$ (see Table S3 in ESI $\dagger$ ) compared to $\mathrm{Li}_{0.8} \mathrm{Ni}_{0.7} \mathrm{Fe}_{0.3} \mathrm{PO}_{4}$. This can be the reason for the better binding of water and lower adsorption energy in $\mathrm{Li}_{0.6} \mathrm{Na}_{0.2} \mathrm{Ni}_{0.7} \mathrm{Fe}_{0.3} \mathrm{PO}_{4}$ compared to $\mathrm{Li}_{0.8} \mathrm{Ni}_{0.7} \mathrm{Fe}_{0.3} \mathrm{PO}_{4}$.

We observed that for different combinations of alkali $\mathrm{Li} / \mathrm{Na}$ and transition metals $\mathrm{Ni} / \mathrm{Fe}$ or $\mathrm{Ni} / \mathrm{Co}$ the calculated adsorption energy of a single water molecule at the (010) surface of the olivine phosphate follows a trend similar to that observed by Gershinsky et $a l^{33}$ for the electrochemical activity of these systems for OER reactions based on overpotential measurements. We found that decreasing adsorption energy follows a trend of decreasing overpotential for the series of olivine phosphate, as shown in Fig. 3 and Table S5 (in ESI). $\dagger$

\section{Conclusions}

We studied the binding of water at the surface of olivine phosphates with mixed alkali metals (Li and $\mathrm{Na}$ ) and mixed TM atoms (Ni and Fe) using DFT. We considered the (010) plane of the olivine phosphate in our surface slab model, where one end is terminated with Li metal atoms and other end is terminated with TM atoms. The computed adsorption energy revealed that water preferably attaches to Ni sites in the absence of alkali ion vacancies. We explained this preference from the DOS of the bare surface where Fe-3d states compose the valence band whereas unoccupied Ni-3d states make up the conduction band, facilitating water binding via $\mathrm{Ni}$ sites. This trend of water adsorption changes to Fe-sites when Li-vacancies are present in the system. This is consistent with the DOS of the bare surface with Li-vacancies, which showed that Fe-3d states form the conduction band. This is also in line with the enhancement in calculated Bader charge at Fe sites in the presence of vacancies. Further we showed that there is qualitative correlation between the calculated adsorption energy of water at the surface and experimentally measured overpotential for the different combinations of mixed alkali and TMs olivine phosphates. Among the various experimentally reported systems considered in this study, $\mathrm{Li}_{0.6} \mathrm{Na}_{0.2} \mathrm{Ni}_{0.7} \mathrm{Fe}_{0.3} \mathrm{PO}_{4}$ with mixed alkali $\mathrm{Li}$ and $\mathrm{Na}$ in presence of Li-vacancies shows best electrocatalytic behavior experimentally and also is the most potent water binder. In 
short, this study provides new insights into the role of transition metals, Na-doping, and the effect of vacancy on the surface reactivity of a series of olivine phosphates with different stoichiometry. Importantly, the current calculations provide insights that may guide future experimental efforts.

\section{Conflicts of interest}

There are no conflicts of interest to declare.

\section{Acknowledgements}

This work was supported by the Israel Science Foundation (ISF) in the framework of the INREP project.

\section{References}

1 A. S. Andersson and J. O. Thomas, J. Power Sources, 2001, 9798, 498-502.

2 S.-Y. Chung, J. T. Bloking and Y.-M. Chiang, Nat. Mater., 2002, 1, 123-128.

3 G. K. P. Dathar, D. Sheppard, K. J. Stevenson and G. Henkelman, Chem. Mater., 2011, 23, 4032-4037.

4 M. S. Islam and C. A. J. Fisher, Chem. Soc. Rev., 2014, 43, 185204.

5 A. K. Padhi, K. S. Nanjundaswamy and J. B. Goodenough, J. Electrochem. Soc., 1997, 144, 1188-1194.

6 J. Wang and X. Sun, Energy Environ. Sci., 2015, 8, 1110-1138. 7 V. Singh, Y. Gershinsky, M. Kosa, M. Dixit, D. Zitoun and

D. T. Major, Phys. Chem. Chem. Phys., 2015, 17, 31202-31215.

8 M. Kosa, D. Aurbach and D. T. Major, Mater. Chem. Phys., 2016, 174, 54-58.

9 T. Muraliganth and A. Manthiram, J. Phys. Chem. C, 2010, 114, 15530-15540.

10 A. Osnis, M. Kosa, D. Aurbach and D. T. Major, J. Phys. Chem. C, 2013, 117, 17919-17926.

11 D. H. Snydacker and C. Wolverton, Phys. Rev. B, 2017, 95, 024102.

12 D. H. Snydacker and C. Wolverton, J. Phys. Chem. C, 2016, 120, 5932-5939.

13 X. Rui, X. Zhao, Z. Lu, H. Tan, D. Sim, H. H. Hng, R. Yazami, T. M. Lim and Q. Yan, ACS Nano, 2013, 7, 5637-5646.

14 S. Ma, Q. Zhu, L. Chen, W. Wang and D. Chen, J. Mater. Chem. A, 2016, 4, 8149-8154.

15 H. Kim, J. Park, I. Park, K. Jin, S. E. Jerng, S. H. Kim, K. T. Nam and K. Kang, Nat. Commun., 2015, 6, 8253.

16 N.-T. Suen, S.-F. Hung, Q. Quan, N. Zhang, Y.-J. Xu and H. M. Chen, Chem. Soc. Rev., 2017, 46, 337-365.

17 Y. Liu, H. Wang, D. Lin, C. Liu, P.-C. Hsu, W. Liu, W. Chen and Y. Cui, Energy Environ. Sci., 2015, 8, 1719-1724.

18 L. Tong, L. Duan, Y. Xu, T. Privalov and L. Sun, Angew. Chem., Int. Ed., 2011, 50, 445-449.

19 W. J. Youngblood, S.-H. A. Lee, Y. Kobayashi, E. A. Hernandez-Pagan, P. G. Hoertz, T. A. Moore, A. L. Moore, D. Gust and T. E. Mallouk, J. Am. Chem. Soc., 2009, 131, 926-927.
20 L. Duan, F. Bozoglian, S. Mandal, B. Stewart, T. Privalov, A. Llobet and L. Sun, Nat. Chem., 2012, 4, 418-423.

21 K. S. Joya, N. K. Subbaiyan, F. D'Souza and H. J. M. de Groot, Angew. Chem., Int. Ed., 2012, 51, 9601-9605.

22 Q. Shi, C. Zhu, D. Du and Y. Lin, Chem. Soc. Rev., 2019, 48, 3181-3192.

23 C. Spöri, P. Briois, H. N. Nong, T. Reier, A. Billard, S. Kühl, D. Teschner and P. Strasser, ACS Catal., 2019, 9, 6653-6663.

24 Z.-P. Wu, X. F. Lu, S.-Q. Zang and X. W. Lou, Adv. Funct. Mater., 2020, 30, 1910274.

25 Z. Lu, H. Wang, D. Kong, K. Yan, P.-C. Hsu, G. Zheng, H. Yao, Z. Liang, X. Sun and Y. Cui, Nat. Commun., 2014, 5, 4345.

26 A. Sivanantham, P. Ganesan, A. Vinu and S. Shanmugam, ACS Catal., 2020, 10, 463-493.

27 T. Y. Ma, J. L. Cao, M. Jaroniec and S. Z. Qiao, Angew. Chem., Int. Ed., 2016, 55, 1138-1142.

28 T. Zhang, Y. Zhu and J. Y. Lee, J. Mater. Chem. A, 2018, 6, 8147-8158.

29 K. Jin, J. Park, J. Lee, K. D. Yang, G. K. Pradhan, U. Sim, D. Jeong, H. L. Jang, S. Park, D. Kim, N.-E. Sung, S. H. Kim, S. Han and K. T. Nam, J. Am. Chem. Soc., 2014, 136, 7435-7443.

30 X. Wu, Y. Lin, Y. Ji, D. Zhou, Z. Liu and X. Sun, ACS Appl. Energy Mater., 2020, 3, 2959-2965.

31 Y. Li and C. Zhao, Chem. Mater., 2016, 28, 5659-5666.

32 Y. Gershinsky and D. Zitoun, ACS Catal., 2018, 8, 8715-8725.

33 Y. Gershinsky, M. Zysler, V. Shokhen, Y. Stone and D. Zitoun, ACS Catal., 2019, 9, 8355-8363.

34 D. Morgan, A. Van der Ven and G. Ceder, Electrochem. SolidState Lett., 2004, 7, A30-A32.

35 M. S. Islam, D. J. Driscoll, C. A. J. Fisher and P. R. Slater, Chem. Mater., 2005, 17, 5085-5092.

36 A. Whiteside, C. A. J. Fisher, S. C. Parker and M. Saiful Islam, Phys. Chem. Chem. Phys., 2014, 16, 21788-21794.

37 S.-i. Nishimura, G. Kobayashi, K. Ohoyama, R. Kanno, M. Yashima and A. Yamada, Nat. Mater., 2008, 7, 707-711.

38 L. Wang, F. Zhou, Y. S. Meng and G. Ceder, Phys. Rev. B: Condens. Matter Mater. Phys., 2007, 76, 165435.

39 E. Fabbri and T. J. Schmidt, ACS Catal., 2018, 8, 9765-9774. 40 G. Hai, H. Gao, G. Zhao, W. Dong, X. Huang, Y. Li and G. Wang, iScience, 2019, 20, 481-488.

41 W. T. Hong, R. E. Welsch and Y. Shao-Horn, J. Phys. Chem. C, 2016, 120, 78-86.

42 X. Huang, J. Wang, H. B. Tao, H. Tian and H. Xu, Chem. Sci., 2019, 10, 3340-3345.

43 J. Rossmeisl, A. Logadottir and J. K. Nørskov, Chem. Phys., 2005, 319, 178-184.

44 J. Rossmeisl, Z. W. Qu, H. Zhu, G. J. Kroes and J. K. Nørskov, J. Electroanal. Chem., 2007, 607, 83-89.

45 F. Song, L. Bai, A. Moysiadou, S. Lee, C. Hu, L. Liardet and X. Hu, J. Am. Chem. Soc., 2018, 140, 7748-7759.

46 D. A. Kuznetsov, B. Han, Y. Yu, R. R. Rao, J. Hwang, Y. Román-Leshkov and Y. Shao-Horn, Joule, 2018, 2, 225244.

47 G. Kresse and J. Hafner, Phys. Rev. B: Condens. Matter Mater. Phys., 1993, 47, 558-561. 
48 G. Kresse and J. Furthmüller, Comput. Mater. Sci., 1996, 6, 15-50.

49 P. E. Blöchl, Phys. Rev. B: Condens. Matter Mater. Phys., 1994, 50, 17953-17979.

50 J. P. Perdew, K. Burke and M. Ernzerhof, Phys. Rev. Lett., 1996, 77, 3865-3868.

51 A. I. Liechtenstein, V. I. Anisimov and J. Zaanen, Phys. Rev. B: Condens. Matter Mater. Phys., 1995, 52, R5467-R5470.
52 S. L. Dudarev, G. A. Botton, S. Y. Savrasov, C. J. Humphreys and A. P. Sutton, Phys. Rev. B: Condens. Matter Mater. Phys., 1998, 57, 1505-1509.

53 V. Mankad and P. K. Jha, AIP Adv., 2016, 6, 085001.

54 W. Tang, E. Sanville and G. Henkelman, J. Phys.: Condens. Matter, 2009, 21, 084204.

55 G. Henkelman, A. Arnaldsson and H. Jónsson, Comput. Mater. Sci., 2006, 36, 354-360. 